\title{
23. FRACTURES, POROSITY, AND STRESS IN THE DOLERITES OF HOLE 504B, COSTA RICA RIFT ${ }^{1}$
}

\author{
Philippe A. Pezard, ${ }^{2}$ Keir Becker, ${ }^{3}$ André Revil, ${ }^{4}$ Mariem Ayadi, ${ }^{2}$ and Peter K. Harvey ${ }^{5}$
}

\begin{abstract}
Downhole measurements were recorded within the complete basement section of Hole 504B during ODP Leg 148. Because of poor core recovery, these data are essential for understanding the structural context of this deep borehole. A much better understanding of the tectonic, thermal, hydrological, and alteration regimes of the sheeted dike complex is required to evaluate whether further penetration is within reach of future drilling legs.

The set of geophysical measurements from Hole 504B has been analyzed, and 4500 traces of fractures from FMS images were mapped over the bottom $167 \mathrm{~m}$ of the hole. Steep to near-vertical structures dominate and are oriented mainly in a $15^{\circ} \mathrm{N}$ strike direction at the base of the hole, that of maximum horizontal stress direction. From electrical resistivity, three porosity estimates were computed (1) on the basis of the Archie formula, (2) taking into account the presence of clays and the associated contribution of counter-ions to total rock conductivity, and (3) from the difference between two electrical resistivity measurements with different depths of investigations. Whereas the different estimates are in reasonable agreement and compare favorably with measurements made on core, the differences are indicative of the origin and structure of the inferred high porosity zones. Although subvertical conductive structures dominate throughout the sheeted dikes, many might be related to drilling. Subhorizontal structures are more numerous in the upper part. A correlation is obtained between changes in thermal gradient recorded at the end of Leg 140 and relatively high porosity sections, probably associated with fractures and relatively high permeability.

In all, this integrated description of the fractured sheeted dike complex of Hole 504B provides a more dynamic understanding of the penetrated structure. Many of the steep features coincide in azimuthal direction with that of borehole enlargements, which might arise for failures generated in tension. These borehole enlargements developing in the direction of tensile failure confirm earlier determinations of $\mathrm{SH}_{\max }$ orientation. It is therefore likely that borehole enlargements and near-vertical fracturing originate from specific cooling of the hole.
\end{abstract}

\section{INTRODUCTION}

The main objective of Leg 148 was to deepen through the dike/ gabbro transition Deep Sea Drilling Project (DSDP)/Ocean Drilling Program (ODP) Hole 504B, in the eastern equatorial Pacific. Before Leg 148, Hole 504B was already the deepest scientific borehole in the ocean, extending $2 \mathrm{~km}$ below seafloor under $3474 \mathrm{~m}$ of water. It is the only hole to penetrate through the volcanic section into the underlying sheeted dike complex, and Site 504 has over the years become the in situ reference section for the physical and chemical structure of the upper oceanic crust.

Site 504 is located on 5.9-m.y.-old crust, $200 \mathrm{~km}$ south of the Costa Rica Rift, the easternmost segment of three forming the Galapagos or "Cocos-Nazca" spreading center. The Costa Rica Rift spreads asymmetrically at an intermediate rate (a half-rate of $3.6 \mathrm{~cm} / \mathrm{yr}$ to the south and $3.0 \mathrm{~cm} / \mathrm{yr}$ to the north; Hey et al., 1977). Basement relief, south of Costa Rica Rift (Nazca Plate), results from the presence of east-west normal faults parallel to the rift axis, which produce north-

'Alt, J.C., Kinoshita, H., Stokking, L.B., and Michael, P.J. (Eds.), 1996. Proc. ODP, Sci. Results, 148: College Station, TX (Ocean Drilling Program).

${ }^{2}$ Laboratoire de Mesures en Forage, Institut Méditerranéen de Technologie, Technopôle de Château-Gombert, F-13451 Marseille Cedex 20, France; and Laboratoire de Pétrologie Magmatique, URA CNRS 1277, Faculté des Sciences et Techniques de Saint-Jérôme, Avenue Escadrille Normandie-Niemen, F-13397 Marseille Cedex 20. France. Pezard: pezard@imtmerl.imt-mrs.fr; Ayadi: ayadi@imtmer1.imt-mrs.fr

${ }^{3}$ Marine Geology and Geophysics, Rosenstiel School of Marine and Atmospheric Science, 4600 Rickenbacker Causeway, University of Miami, Miami, FL 33149-1098, U.S.A. kbecker@rsmas.miami.edu

${ }^{4}$ Ecole et Observatoire de Physique du Globe, 5 rue René Descartes, F-67084 Strasbourg Cedex, France, andre@climont.u-strasb.fr

${ }^{5}$ Borehole Research, Department of Geology, University of Leicester, LE1 7RH, United Kingdom. pkh@leicester.ac.uk dipping half-graben structures with blocks tilted less than $5^{\circ}$ and separated by ridges 1 to $2 \mathrm{~km}$ wide (Langesth et al., 1988). Site 504 was located at the center of a spreading segment, which is significant in terms of magmatic and tectonic processes. This, in turn, affects hydrothermal alteration processes and the physical structure of the underlying crust.

Before Leg 148, six DSDP and ODP legs contributed to the 2000.4 mbsf depth of Hole 504B (Fig. 1). The hole penetrates 274.5 $\mathrm{m}$ of sediments, a $571.5 \mathrm{~m}$ volcanic section consisting of pillows, massive flows, breccias and a few dikes, a $209 \mathrm{~m}$ transition zone from extrusives into intrusives, and $945.4 \mathrm{~m}$ of dikes and massive units, that are interpreted to constitute the sheeted dike complex. The core recovery averaged $29.8 \%$ in the volcanic section and $14.3 \%$ in the sheeted dikes. During Leg 148, an additional $110.6 \mathrm{~m}$ were drilled through massive dolerites, penetrating from 2000.4 to $2111.0 \mathrm{mbsf}$, for an average recovery of $10.4 \%$.

Deeper penetration was prevented when the drill string encountered what appears to be a fault and became stuck. In petrological, chemical, and metamorphic character, the recovered rocks are a continuation of the sheeted dike complex drilled on previous legs. Because of the very low core recovery near the bottom of the hole, an extensive program of downhole measurements was conducted at the end of Leg 148. The continuous geophysical measurements and highresolution borehole wall images produced by the Formation MicroScanner (FMS) are now essential for analyzing and understanding the structure of this unique deep section of oceanic crust.

With repeated and seemingly increasing difficulties encountered while drilling the bottom $600 \mathrm{~m}$ of the hole, it is important to assess from the data set whether these difficulties are caused by the extreme nature of the environment, or if minor technological changes may allow future drilling campaigns to proceed deeper, through the dikegabbro transition. Such a study initially requires a combined analysis 


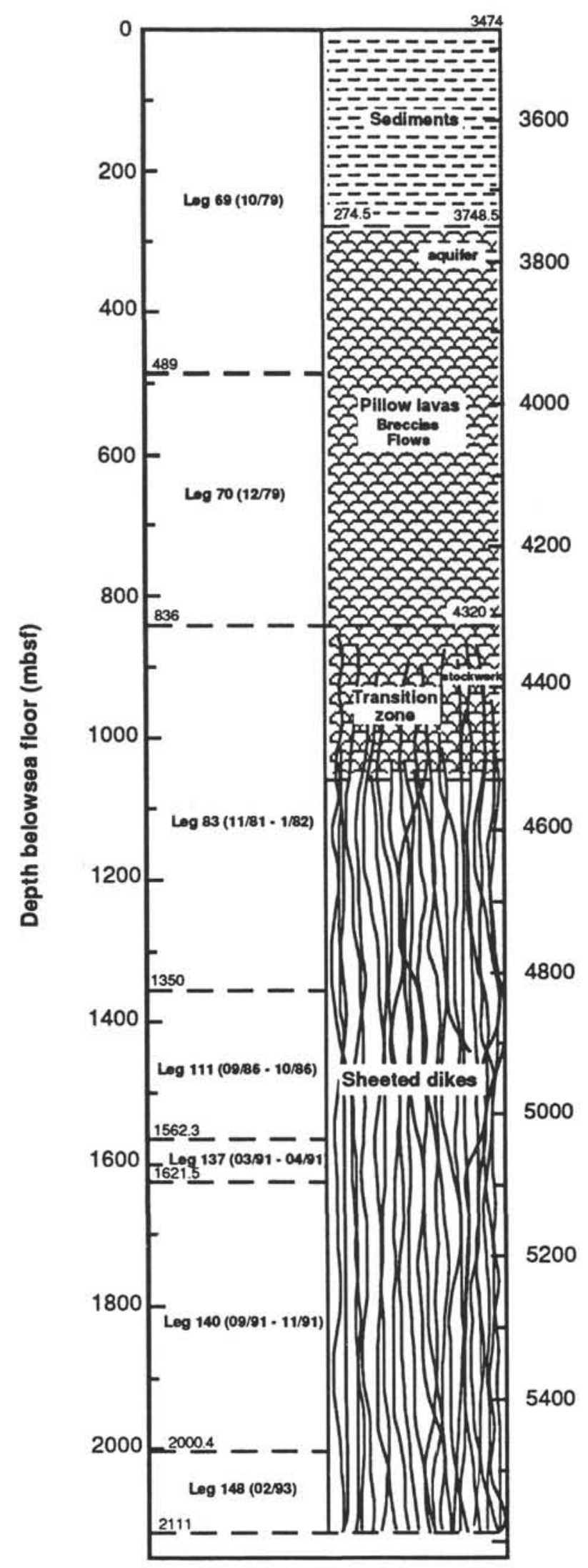

Figure 1. Schematic diagram of Hole 504B drilling history and lithostratigraphy after Leg 148. The depth is given both in meters below seafloor (mbsf) and in meters below drill floor (mbdf). of the penetrated structures with respect to processes to which the rock formation is subjected. These fluxes involve high deviatoric stresses in the vicinity of both an active ridge and a subduction zone, high heat-flow constraining drilling and downhole measurement technologies, and possibly high pressure in front of a fault zone, for example, although the latter has not been recognized in the hole yet.

This paper concentrates on the sheeted dikes complex exclusively, dealing with the lowermost $1200 \mathrm{~m}$ of the hole, from 900 to 2100 mbsf. Downhole measurements are first analyzed in terms of structure with the determination of porosity profiles and main fracturing orientation, then in terms of dynamics with a temperature record obtained at the end of ODP Leg 140, and stress field as observed from the shape of the borehole. The FMS borehole wall images recorded during Leg 148 in Hole 504B are used briefly to support this analysis, as only the bottom $200 \mathrm{~m}$ of the recorded data have presently been analyzed in terms of geometry with a precise description of fracturing vs. depth.

\section{DOWNHOLE MEASUREMENTS}

During Leg 148, a series of downhole measurements (including Schlumberger geophysical sensors, the FMS, and magnetometer, temperature, and vertical seismic profiles) were successfully conducted in Hole 504B (Alt et al., 1993). Below $1900 \mathrm{mbsf}$, the temperature gradient is about $49^{\circ} \mathrm{C} / \mathrm{km}$. The profile is linear where the temperature reaches a recorded maximum of $190^{\circ} \mathrm{C}$. Compressionalwave velocity log data are discussed in Wilkens et al. (this volume), with values greater than $5.0 \mathrm{~km} / \mathrm{s}$ in the dikes, eventually reaching 6.8 $\mathrm{km} / \mathrm{s}$ below $2000 \mathrm{mbsf}$ (Fig. 2). Over the same interval, electrical resistivity values range up to $6000 \Omega \mathrm{m}$. The natural radioactivity profile $(G R)$ barely shows any character below $1000 \mathrm{mbsf}$ because of the very low radioactivity of the penetrated formation, close to the detection level of the sensor. Above, GR peaks result from local potassium concentration in secondary minerals, in response to fluid circulation induced by hydrothermal alteration of the basalts. $G R$ values consequently may be used as a tracer for paleofluid circulation in the extrusives but cannot be relied upon as such in the intrusive section.

\section{Electrical Resistivity}

The resistivity data were recorded in the hole with a lateral device, the Dual Laterolog (DLL) tool. Lateral devices are accurate at highresistivity values (with an error $<5 \%$ up to $40.000 \Omega \mathrm{m}$ for the DLL), such as those obtained in crystalline formations. The DLL, as described by Ellis (1987), is designed to provide two measurements of electrical resistivity, often referred to as deep (LLd) and shallow (LLs) because of their respective horizontal penetration into the rock.

Corrections have to be made to the raw measurements to remove the contribution of the saline borehole fluid to the raw data. Deep into the sheeted dike complex, electrical resistivities above $1000 \Omega \mathrm{m}$ are frequently obtained where the borehole temperature exceeds $170^{\circ} \mathrm{C}$. Seawater electrical conductivity is then greater than $20 \mathrm{~S} / \mathrm{m}$ according to von Herzen et al. (1983), and more than 4 orders of magnitude separate rock and borehole fluid resistivities. The borehole signal is then very large and should be accounted for. Figure 3 shows the corrected DLL data over the bottom $1200 \mathrm{~m}$ of the hole.

The sheeted dike complex is easily recognized from overlying extrusives, as the electrical resistivity sharply increases below $850 \mathrm{mbsf}$ when entering the lithological "transition zone." At about $950 \mathrm{mbsf}$, the resistivity profile picks up a high frequency character that continues down to $1150 \mathrm{mbsf}$. This high frequency appearance is typical of the transition zone and might be used to evaluate its actual thickness (about $200 \mathrm{~m}$ ). The shallow measurement (LLs), more sensitive to the presence of the conductive borehole than the deep one (LLd), is considerably higher throughout (Fig. 3) with respect to the raw data (Fig. 2 ), whereas the LLd is slightly lower. 

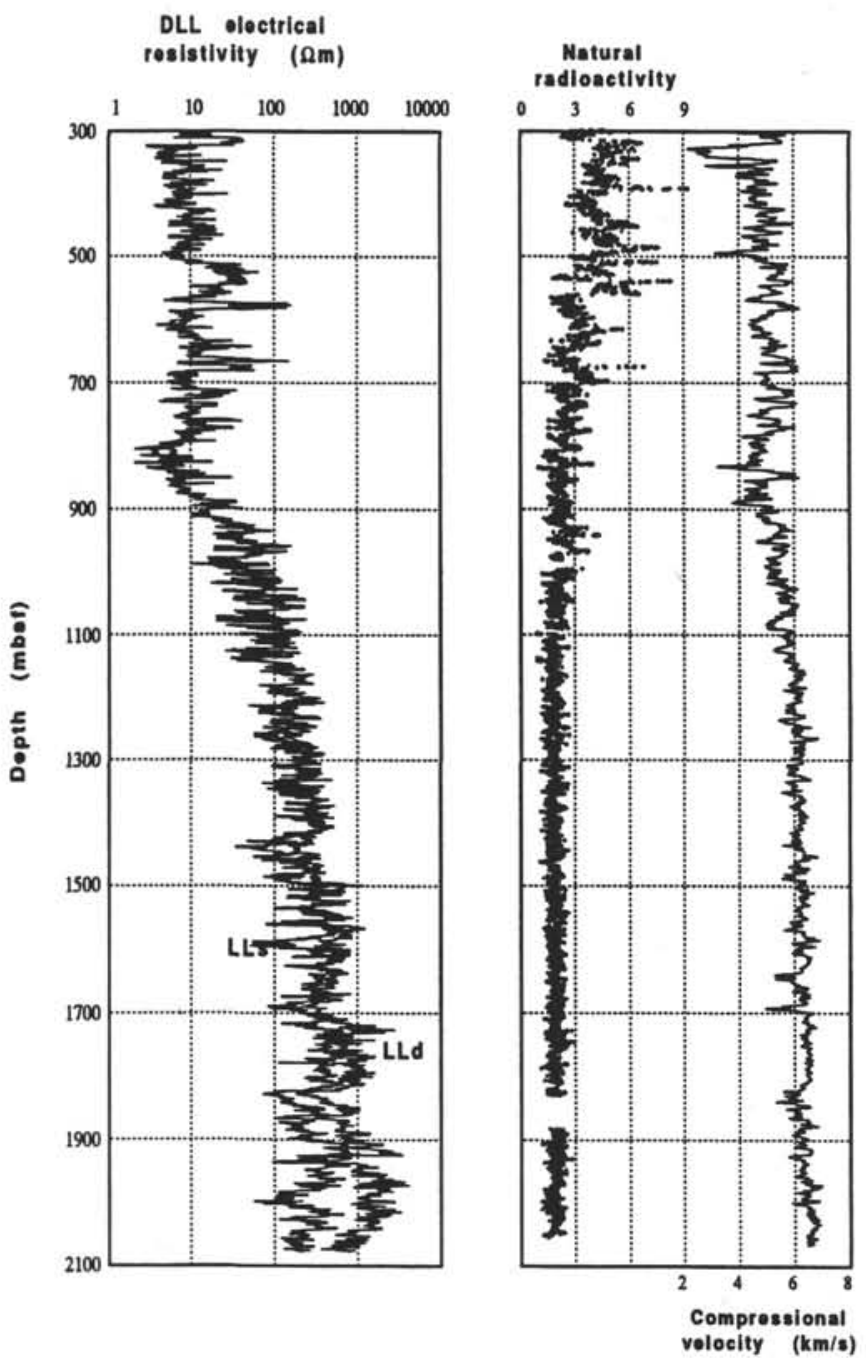

Figure 2. Electrical resistivity measurements recorded with the Dual Laterolog tool (DLL) in Hole 504B, natural radioactivity (GR), and acoustic velocity $\left(V_{p}\right)$ profiles.

The difference between the two curves is small down to about 1830 mbsf. Below this depth, the difference between the two curves remains unexpectedly important, especially in sections where the hole is observed to elongate substantially (Fig. 3; near 1600 and 2000 mbsf). From 900 mbsf, the electrical resistivity increases almost continuously down to $1410 \mathrm{mbsf}$, then follows a more irregular pattern with measurements under $100 \Omega \mathrm{m}$ spaced every 100 to $200 \mathrm{~m}$ downhole, on average. These electrical resistivity decreases are probably associated with porosity increases related to the presence of fractures, or that of clay minerals associated with paleofluid circulation.

\section{FMS Electrical Images}

FMS images were recorded over the entire length of Hole 504B basement during Leg 148. Except for the bottom $14 \mathrm{~m}$ where images from all the pads were obtained, FMS images consist only of three images, covering on average $15 \%$ of the overall surface of the hole. Since the end of Leg 148, the FMS analysis in the sheeted dike complex of Hole 504B has been restricted to the interval spanning 1900 to $2079 \mathrm{mbsf}$, because of limited software availability. As a consequence, FMS data and images are used sparsely in this paper, except in the $200 \mathrm{~m}$ located at the bottom of the hole, elsewhere described in detail by Ayadi et al. (this volume).

The FMS creates a picture of the borehole wall by mapping its resistivity using an array of small, pad-mounted electrodes (Lüthi and

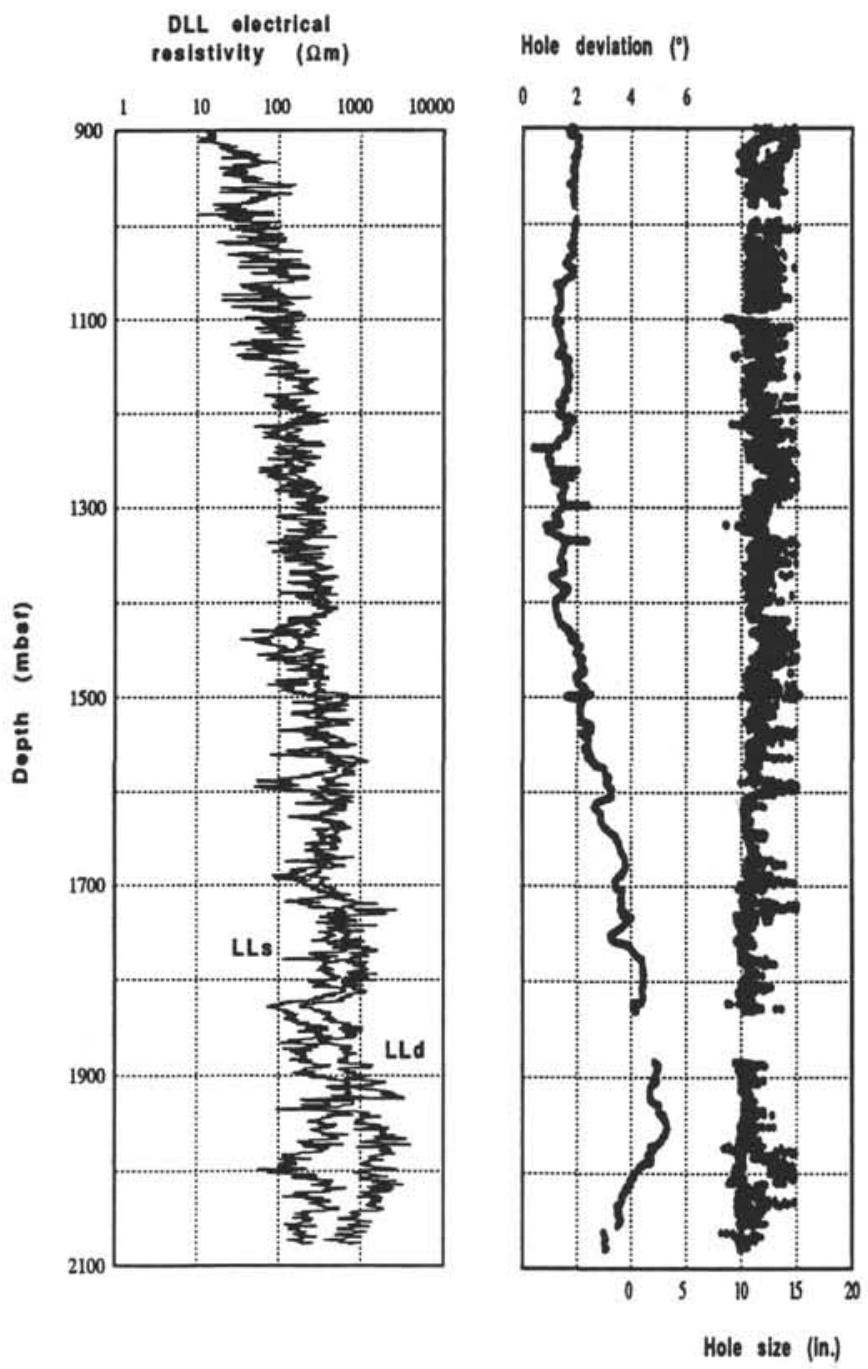

Figure 3. Electrical resistivity measurements recorded with the Dual Laterolog tool (DLL) and corrected for hole signal. Hole deviation and size are derived from the calipers and inclinometry module of the FMS in the sheeted dikes complex of Hole 504B.

Banavar, 1988). The slim hole configuration developed for ODP (Pezard et al., 1990) uses four pads, each with 16 buttons and a single pass of the tool maps about $22 \%$ of a $25.4-\mathrm{cm}$-diameter borehole (10 in.). Each electrode is oriented in space with three-axis accelerometers and flux-gate magnetometers, making it possible to derive the strike and dip of geological structures.

Because of electrode geometry, the tool has a moderately shallow depth of investigation, only a few centimeters beyond the borehole wall. FMS data are recorded every $2.5 \mathrm{~mm}$ as the tool moves up the borehole, and the vertical resolution of individual features is about one centimeter. The tool can, however, detect thinner features provided they have sufficient resistivity contrast to the surroundings matrix. The images recorded with the FMS show conductivity changes, particularly with beds different in nature and the presence of fractures, either open or mineralized.

FMS data processing and analysis is described by Ayadi et al. (this volume). The images were analyzed with FRACVIEW, a Schlumberger ${ }^{\mathrm{TM}}$ interpretative software package that allows the interactive display and analysis of oriented images. The fracture analysis method is presented in Lüthi and Souhaité (1990) and, beyond detection and mapping, aimed at providing a quantitative evaluation of "fracture aperture" from electrical images. Ayadi et al. (this volume) have analyzed and mapped about 4500 fracture traces between 
1900 and 2079 mbsf, strictly in terms of geometry. To organize this large data set, the fracture traces were classified in terms of dip angle constituting several sets. One of these sets comprises steep to vertical single traces (with dips $\geq 85^{\circ}$ ) detected on one of the pads only.

For electrical resistivity correction, hole size is obtained from FMS orthogonal calipers that have a maximum opening of 15 in. The hole was generally in good condition over the bottom $1000 \mathrm{~m}$. Larger hole sizes were measured from 900 to $1100 \mathrm{mbsf}$. The overall inclination of the borehole derived from FMS inclinometer data remained very low throughout (Fig. 3), first decreasing slightly down to $1.0^{\circ}$ at about 1250 to $1400 \mathrm{mbsf}$, then increasing to $5.5^{\circ}$ at $1950 \mathrm{mbsf}$. Below this depth, the inclination of the hole decreases abruptly to reach a value of $3.0^{\circ}$ at the present bottom of the hole. This abrupt change, as well as the large hole size measured near 200 mbsf, suggests that the hole might have encountered a change in stress field environment at about $1950 \mathrm{~m}$.

\section{POROSITY EVALUATION}

Several estimates of porosity may be obtained from DLL electrical resistivity data. A first estimate can be derived directly from the deep penetrating measurement (LLd) with Archie's formula (Archie, 1942; Brace et al., 1965; Becker, 1985), and may be considered as representative of the "total" porosity of the rock. A second estimate may be derived when accounting for surface conductivity caused by the presence of clay minerals (Pezard, 1990; Revil et al., this volume), and considered then as an estimate of the porous fraction where fluids (seawater in this case) are free to move away from surface effects.

Finally, a third estimate may be derived from the particular geometry of the DLL. After correction for borehole effects, the difference between the two measurements (LLs and LLd) are used to compute two minimum values of fracture porosity (Pezard and Anderson, 1990) referred to as "horizontal" and "vertical." Indirectly, the last estimate provides an evaluation of the degree of anisotropy of the penetrated formation vs. depth. Minimum porosity values are computed as the simultaneous presence of horizontal and vertical structures might yield a conflict and lead to a nearly null estimate. The three methods are outlined below and compared on the basis of profiles obtained in Hole 504B.

\section{Archie's Formula}

The deep penetrating measurement (LLd) is less sensitive to borehole effects than the shallow one (LLs) and, as such, can be related to the total porosity of the rock when derived from Archie's formula with $a=1$ and $m=2$ (Archie, 1942; Brace et al., 1965; Becker, 1985). An estimate of "total porosity" from resistivity (referred as $\emptyset_{a}$ in the following) is then obtained, although the LLd is mostly sensitive to the horizontal resistivity of the rock and, hence, affected preferentially when subhorizontal conductive fractures are encountered.

\section{Surface Conductivity and Tortuosity}

The full expression for the total conductivity of a rock formation consists of two terms: a volume and a surface conductivity (Waxman and Smits, 1968; Clavier et al., 1986; Pape and Worthington, 1983; Johnson and Schwartz, 1989; Pezard, 1990; Revil et al., this volume). If volume conduction and surface conduction are considered to be parallel, the total conductivity of the rock can be written as follows:

$$
\sigma=\frac{1}{F} \sigma_{w}+\sigma_{s},
$$

where $\sigma_{w}$ is the saturating fluid (seawater) conductivity, $\sigma_{s}$ the surface conductivity resulting from the electric double layer (Clavier et al., 1986; Ucok, 1980), and $F$ the formation factor of the rock. It is an intrinsic property of the porous medium depending upon its texture and three-dimensional topology (i.e., the distribution of pore and crack sizes, connectivity, tortuosity).

The convexity of the $\sigma$ vs. $\sigma_{w}$ plot (Waxman and Smits, 1968; Clavier et al., 1986; Pape et al., 1985; Pezard, 1990) can be explained by the different tortuosities between surface and volume conduction paths (Johnson and Sen, 1988). As $\sigma_{w}$ increases, dominant current paths shift from surface to pore and therefore are subjected to different tortuosities. As only a fraction $f_{a}$ (with $0 \leq f_{a} \leq 1$ ) of the clay actually participates in surface conduction, surface conductivity may be obtained after Clavier et al. (1986) with

$$
\sigma_{s}=\frac{\beta f_{a} Q_{v}^{(c)}}{F},
$$

where $\beta$ is the equivalent conductance of the counter-ions absorbed onto pore surfaces, and $Q_{v}^{(c)}$ the cation exchange capacity of the rock expressed per unit pore volume (Clavier et al., 1986). Standard analytical models, used by Pape et al. (1985) for granite, and Wilkens et al. (1988) and Pezard (1990) for oceanic basalts, have represented surface conductivity with

$$
\sigma_{s}=\frac{\beta \cdot Q_{v}^{(c)}}{F \tau_{s}^{2}},
$$

where $\tau_{s}{ }^{2}$ is a factor related to the tortuosity of pore surface (Pape et al., 1985). This parameter can be seen as the "excess tortuosity of the pore surface."

As a consequence, $F_{s}=F \cdot \tau_{s}{ }^{2}=F / f_{a}$ is the formation factor associated with the surface conduction, and the lower limit for the surface tortuosity is one. The notion of "connected clay sites" $\left(f_{a}\right)$ pertains to that of percolation theory, and it is inversely related to that of tortuosity (Gueguen and Dienes, 1989). Volume tortuosity $\tau_{V}{ }^{2}$ is defined by

$$
F=\tau_{V}^{2} / \varnothing
$$

From laboratory measurements on samples extracted from the sheeted dikes, Revil et al. (this volume) reports values of $\tau_{s}^{2}$ as high as 31 , which equates to $f_{a} \approx 2 \%$ and suggests the presence of complicated pore surfaces in this section of Hole 504B.

After Carman (1956) and numerous others, it appears that the connected porosity may be related to the formation factor by the Winsauer and McCardell equation (1953), a generalization of Archie's formula (1942):

$$
F=a \cdot \phi^{-m},
$$

in which $a$ and $m$ are called, by extenuation, the "Archie parameters." The factor $a$ may then be seen as the mean volume tortuosity of the formation. Revil et al. (this volume) reports $a \approx 16 \pm 2$ and $m$ $\approx 0.94$ for a set of doleritic samples, which is close to the $a \approx 10$ and $m \approx 1.00$ of Pezard (1990), indicating that the conducting pore space of doleritic rocks is mainly composed of high aspect-ratio cracks and micro cracks.

\section{Clay-corrected Porosity Estimates}

On the basis of the theoretical approach described above, electrical conductivity and porosity may be related through bulk tortuosity $\tau_{V}$ and total cation exchange capacity (CEC). With Equation 4 and assuming that $\varnothing<<1$, Equations 1 and 3 become 


$$
\sigma=\frac{\phi}{\tau_{v}{ }^{2}} \sigma_{w}+2.8010^{-3} \frac{C E C_{(C)}}{\tau_{v}{ }^{2}},
$$

where $C E C_{(C)}$ is the cation exchange capacity in meq/100 g. Surface conductivity was computed with a matrix density, $\rho_{m} \approx 2.90 \mathrm{~g} / \mathrm{cm}^{3}$, a counter-ion mobility $\beta=2.5 \cdot 10^{-8} \mathrm{SI}$, and a mean surface tortuosity $\tau_{s}^{2}=25$.

Equation 6 can now be used to determine in situ porosity profiles from DLL resistivity measurements, providing that cation exchange capacity in the formation and the temperature dependence of both surface (clay counter-ions) and volume (seawater) components are known. For CEC, Clavier et al. (1986) mention that a strong correlation may be found between gamma-ray count rate divided by porosity and $Q_{V}$. Natural radioactivity $(G R)$ may then eventually be used to estimate the CEC (not $Q_{v}$ ) in situ, the proportionality constant being determined from laboratory and in situ measurements.

Revil et al. (this volume) demonstrate that the temperature dependence of dolerite samples from Hole 504B is linear over the considered range $\left(20^{\circ}-200^{\circ} \mathrm{C}\right)$, both in the surface and volume conduction terms with

$$
\begin{gathered}
\sigma_{w}(M, T)=\sigma\left(M, T_{0}\right)\left[1+\alpha_{w}\left(T-T_{0}\right)\right], \\
\beta(T)=\beta\left(T_{0}\right)\left[1+\alpha_{s}\left(T-T_{0}\right)\right],
\end{gathered}
$$

where $T_{0}=20^{\circ} \mathrm{C}, \alpha_{w} \approx(0.023)^{\circ} \mathrm{C}^{-1}$, and $\alpha_{s} \approx(0.040)^{\circ} \mathrm{C}^{-1}$. As a consequence, whereas surface conductivity in the extrusives average often less than $10 \%$ of the volume conductivity of analyzed samples for seawater salinity and at room condition (Pezard, 1990), $\alpha_{s}>\alpha_{w}$ implies that $\sigma_{s}$ may be far from negligible at temperatures encountered in the sheeted dikes complex of Hole 504B. Revil et al. (this volume) consequently rewrite Equation 6 with temperature-dependent terms as

$$
\sigma(M, T)=\frac{\phi}{\tau_{V}^{2}} \sigma_{w}(M, T)+2.8010^{-3} \frac{C E C_{(C)}}{\tau_{V}^{2}} \frac{\beta(T)}{\beta\left(T_{0}\right)},
$$

where $\sigma_{w}(M, T)$ is given by Equation 7 at seawater salinity, and where $\beta(T) / \beta\left(T_{0}\right)$ by Equation 8 . As the total conductivity $\sigma(M, T)$ is directly measured in the hole with the DLL, the porosity $\emptyset$ and volume tortuosity $\tau_{V}{ }^{2}$ are the only two unknowns of Equation 9, providing that $C E C_{(c)}$ can be derived from natural radioactivity $(G R)$.

\section{DLL-derived Fracture Porosity}

A third porosity estimate might be obtained from the difference between the two DLL measurements (Pezard and Anderson, 1990), after correction for hole size effect. As a result of the tool geometry and strong focusing, the presence of subhorizontal conductive features decreases the deep measurement more than the shallow one. To the opposite, the deep resistivity measurement (LLd) reads always higher than the shallow one (LLs) in front of subvertical structures. For example, the large difference between corrected shallow (LLs) and deep (LLd) measurements in the bottom $250 \mathrm{~m}$ of the hole (Fig. 3 ) suggest the dominating presence of subvertical features.

This method, based on a comparison of DLL measurements, provides an estimate of porosity in anisotropic media. The estimate is a minimum one because of potential conflict between horizontal $\left(\emptyset_{h-D L L}\right)$ and vertical $\left(\emptyset_{v-D L L}\right)$ structures. When associated, horizontal and vertical structures might cancel out, and a minimum estimate only of fracture porosity is obtained $\left(\varnothing_{t-D L L}\right)$. The three estimates of porosity are computed and compared below.

\section{POROSITY STRUCTURE}

On the basis of Pezard (1990) and Revil et al. (this volume), two values of volume tortuosities (10 and 16, respectively, for these two
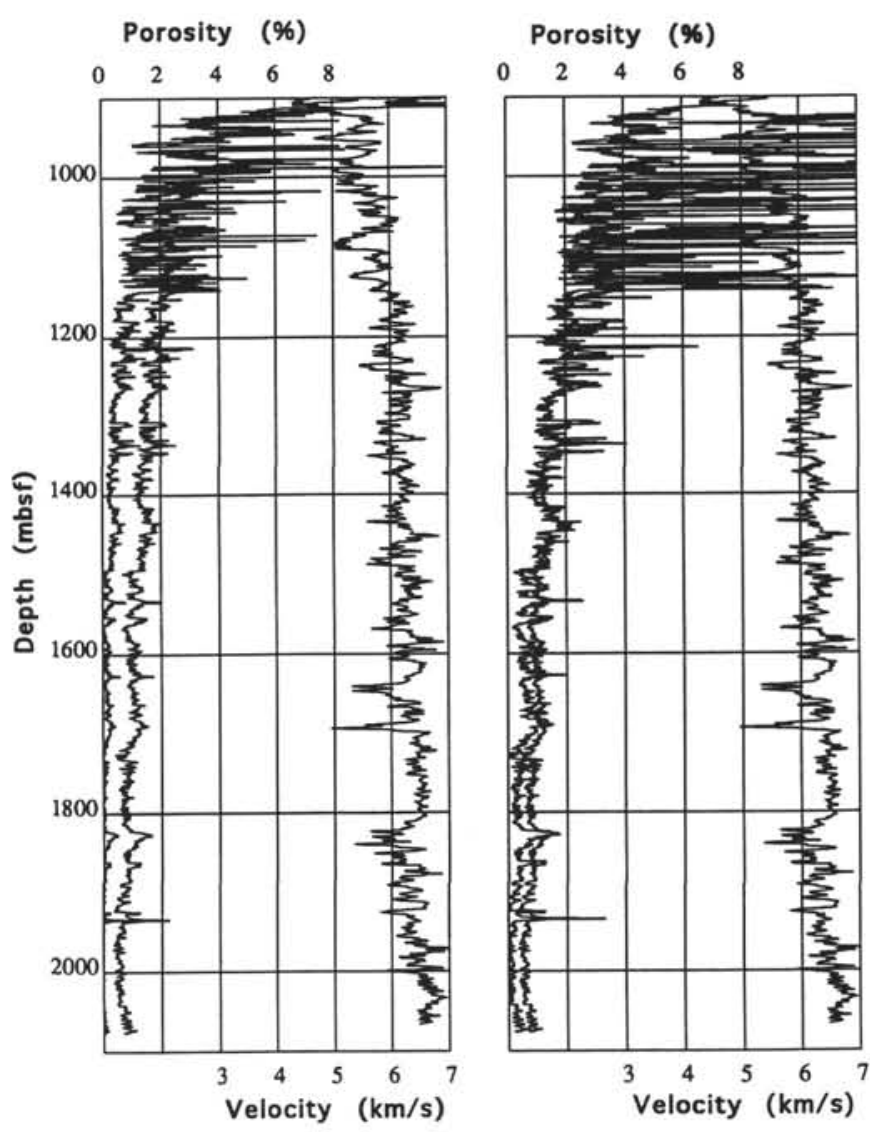

Figure 4. Estimates of basement porosity with "total" porosity derived from Archie's formula (for the larger values) and clay-corrected estimate (for the smaller ones) computed with a pore-volume tortuosity $\tau_{V}{ }^{2}$ of 10 (left) and $\tau_{V}^{2}$ $=30$ (right). In each diagram, acoustic velocity of compressional waves is used as a reference.

studies) were tested to compute clay-corrected estimates of "free-fluid" porosity. These values obtained at surface were chosen as minimum, as it may be expected that core decompression from great depth will allow cracks to open and volume tortuosity to decrease.

Natural radioactivity in the sheeted dikes average about 2.0. As measured CEC for Hole 504B dolerite samples average about the same value in the laboratory (Pezard, 1990; Revil et al., this volume), a direct relationship $C E C_{(c)}=G R$ was chosen to evaluate $C E C_{(c)}$. As negative porosity estimates were obtained in the lower part of the hole, lower values for $C E C_{(c)}$ were requested. Satisfactory results was obtained with $C E C_{(c)}=(G R / 4)$, and this formula was kept through the analysis. This ratio may result from the fact that CEC measurements are often found to overestimate surface properties, in relation with excessive grinding of the samples.

\section{Clay-corrected Estimates}

Three different values of volume tortuosity were used to estimate porosity in the dikes of Hole 504B, with extreme values of 10 and 30 . Whereas $\tau_{V}{ }^{2}=10$ provides a reasonable estimate down to $1700 \mathrm{mbsf}$, numerous negative values are obtained below (Fig. 4). $\tau_{v}{ }^{2}=30$ was consequently chosen for the lower $400 \mathrm{~m}$ of the hole, and again reasonable number are obtained here. However, whereas the former provides acceptable values in the upper $300 \mathrm{~m}$ of the dikes, the latter does not. As volume tortuosity $\left(\tau_{V}{ }^{2}\right)$ is be related to crack aperture, hence to confining stresses, and to establish a continuity between extreme values, an intermediate value with $\tau_{v}{ }^{2}=20$ was chosen to cover the "intermediate" depth range of the analyzed interval, from 1300 to 1700 mbsf (Fig. 5). 
A

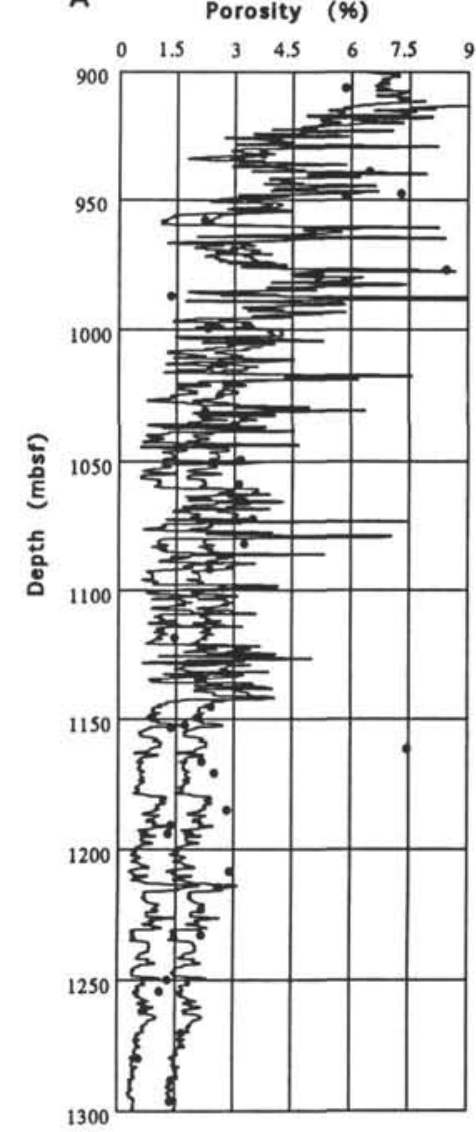

B

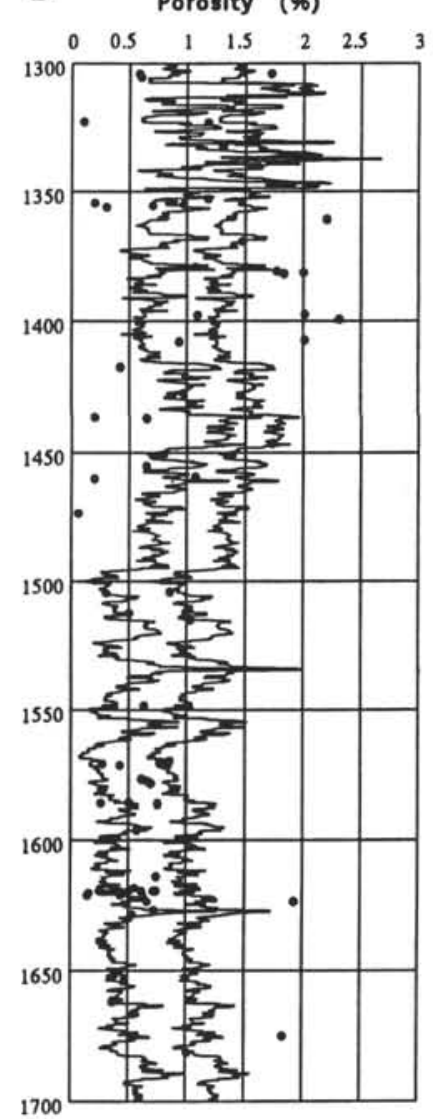

C

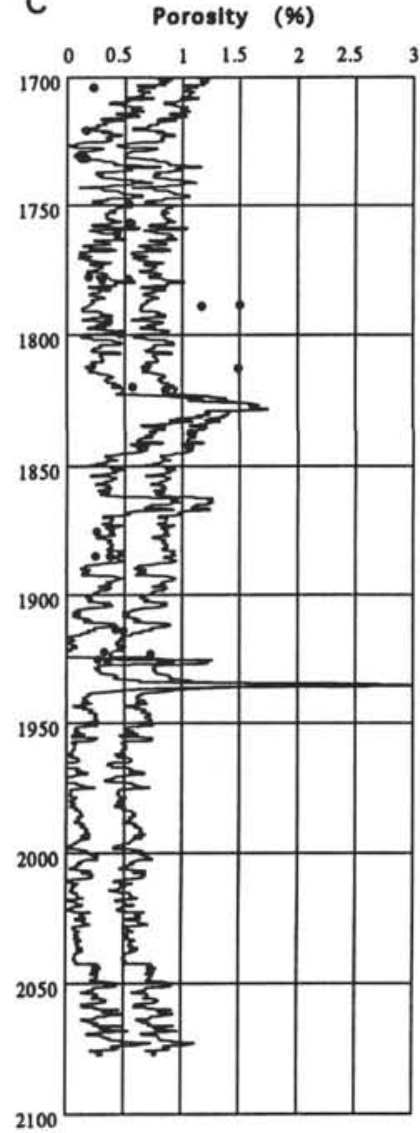

Figure 5. A. From 900 to 1300 mbsf, "total" porosity derived from Archie's formula (for the larger values), clay-corrected estimate (for the smaller ones) computed with a pore-volume tortuosity $\tau_{V}^{2}$ of 10 , and shipboard core measurements. B. From 1300 to 1700 mbsf, same curves with $\tau_{V}{ }^{2}=20$. C. From 1700 to 2100 mbsf, same curves with $\tau_{v}^{2}=30$.

Clay-corrected estimates are systematically lower than Archie estimates $\emptyset_{a}$, except in the top section where $\tau_{V}{ }^{2}=30$, which is not appropriate. The clay minerals consequently appear to account for $40 \%$ to $80 \%$ of the derived porosity throughout. The Archie "total" porosity ranges from $0.5 \%$ to $2.0 \%$ below 1300 mbsf (Fig. 4), but clay-corrected porosity estimates are in closer agreement with measurements made on core (Fig. 5). The porosity appears to decrease in a very uniform manner with depth, with a few high values obtained in regions where lower acoustic velocities were measured. The high-frequency character of physical properties in the upper dikes, down to 1140 mbsf is emphasized in porosity estimates (Fig. 4).

One of the main features in the analyzed interval appears to be a pair of sudden increases in porosity estimates near 1935 mbsf (Fig. 5 ). The abruptness of these events where free-fluid porosity locally equals Archie "total" porosity, as well as a "reversal" in resistivity profiles (with LLs > LLd; Fig. 3), indicate the presence of a pair of subhorizontal structures. This may suggest the presence of two subhorizontal features at depth that are also the site of a compressional wave velocity decrease (Fig. 2) and, moreover, that of a change in hole deviation rate, the only one in the sheeted dike complex (Fig. 3). If correct, this interpretation should be confirmed by DLL-derived porosity estimates.

\section{DLL-derived Estimates}

Relatively high values of "vertical fracture porosity" $\left(\emptyset_{v-D L}\right)$ averaging about $0.1 \%$ are obtained throughout (Fig. 6), with values up to $0.8 \%$ at the bottom of the hole over a 25 -m-long interval (1980 to $2005 \mathrm{mbsf}$ ). Such values are indicative a strong subvertical orientation of the conducting pathway in the sheeted dikes. The somewhat regular spacing (about $125 \mathrm{~m}$ ) detected in DLL data corresponds to zones of high vertical porosity estimates.

Subhorizontal structures are mostly present in the upper part of the considered section, in particular in the transition zone down to $1150 \mathrm{mbsf}$, thereby explaining the high frequency character of the resistivity data in this zone. Discrete intervals with horizontal features are obtained from 1150 down to $1735 \mathrm{mbsf}$, where horizontal fracturing disappears, with the exception of a single large peak located at 1935 mbsf, as expected from earlier discussion. The smaller porosity peak, located at $1926 \mathrm{mbsf}$ is not detected, possibly because of the conflicting presence of subvertical structures in this zone. Together with the sudden change in hole deviation at about $1950 \mathrm{mbsf}$ and hole caving in a single direction below (Fig. 4), this strong subhorizontal signal may be indicative of a change in stress regime from above the subhorizontal structures at about $1935 \mathrm{mbsf}$.

The stress field in this hole has been determined to be of either compressive or strike-slip nature from the analysis of borehole televiewer (BHTV) images (Moos and Zoback, 1990) and ruptured surfaces in the core from the deeper sections (Alt et al., 1993). The strong subvertical signal inferred from DLL electrical measurements throughout and, in particular, below $1950 \mathrm{mbsf}$ would favor the presence of a strike-slip regime. The very large deviatoric component of this field, with the minimum horizontal one similar to the vertical one and possibly half of the maximum horizontal one (Alt et al., 1993), 


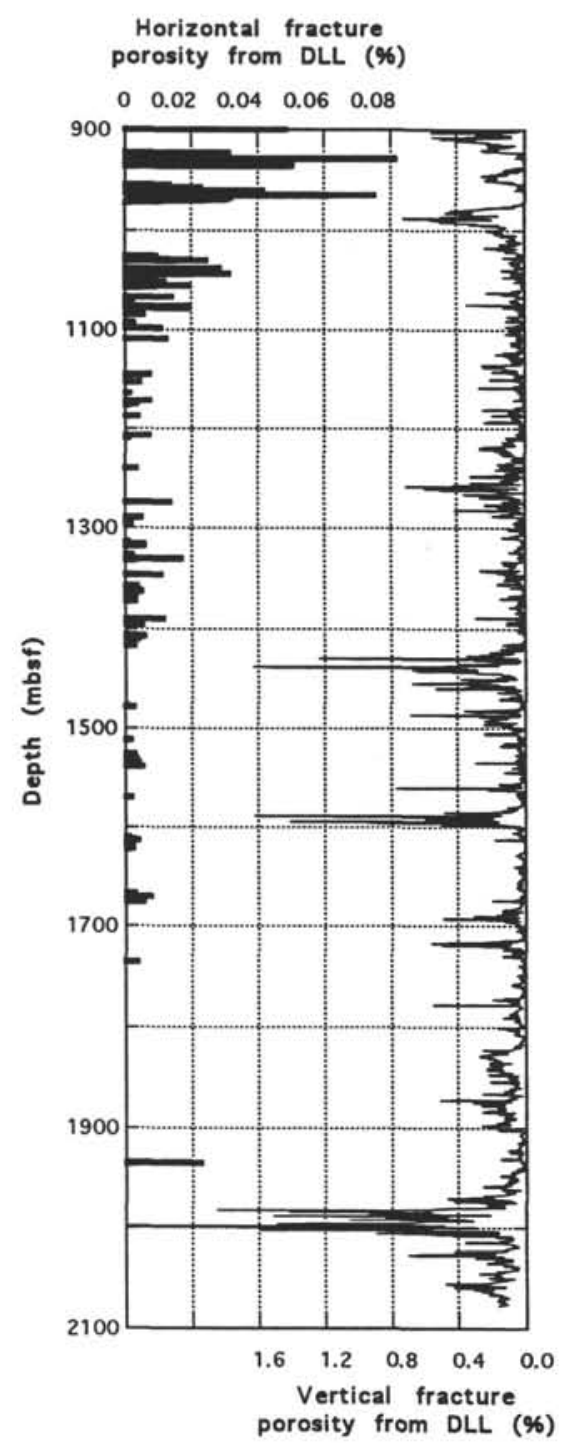

Figure 6. DLL-derived minimum fracture porosity estimates.

could explain the presence of the subvertical conductive pathways detected with the DLL, if sufficient to initiate rock failure in relation to drilling.

\section{DISCUSSION}

If the subvertical feature detected near and above $2000 \mathrm{mbsf}$ is neo-formed, related to the drilling activity under the present stress field, it becomes important to be able to distinguish such features from deep-reaching fracture zones. Figure 7 shows that this interval (1975-2005 mbsf) is one of the few where the DLL-derived estimate is greater than the clay-corrected estimates. In fact, from $1950 \mathrm{mbsf}$ downward, the fracturing appears to be strongly anisotropic, not only subvertical but also organized in terms of strike direction (Ayadi et al., this volume).

In FMS images, the dominant strike direction of detected events $\left(015^{\circ} \mathrm{N}\right)$ between 1900 and $2077 \mathrm{mbsf}$ is close to the maximum horizontal stress obtained by Newmark et al. (1985) and Morin et al. (1990) from BHTV images. Therefore, it is likely that a large majority of the planes mapped from FMS images are either neo-formed or preferentially reopened under present stress conditions at this depth.
A section similar to that of 2000 mbsf is found from 1585 to 1600 mbsf. Here again, the DLL-derived subvertical fracturing is not supported by the clay-correction model, whereas the fracture zone imaged near 1440 mbsf is detected by both methods, for example.

The zone located above 1600 mbsf endured fishing operations during Leg 137, which would indicate that such organized and deepreaching fracturing (at least a few meters, that of DLL investigation) are filled with conductive seawater and, consequently, could only originate in drilling operation. The maxiumum depth reached during Leg 140 was 2000.4 mbsf. At the beginning of Leg 148, hole cooling near total depth to protect the new coring bit could have generated this caving. Such a hypothesis was already proposed in the past for the analysis of BHTV images to explain the presence of borehole enlargements in the direction of maximum horizontal stress (Morin et al., 1990). Such a large degree of fracturing might consequently be induced from the combined action of a strongly deviatoric stress field, and that of cooling the drill hole before coring (to protect the coring bit) or logging (to protect downhole sensors).

The large fracturing anomaly detected above $2000 \mathrm{mbsf}$ with the DLL, if attributed to the large deviatoric component of the stress field, might also indicate that the influence of the stress field could extend away from the near vicinity of the borehole. As a consequence, it is likely that electrical current in our case or, likewise, fluid are or would be biased to flow along this preferential direction outside drilling operations.

\section{Temperature}

A convenient method to detect deep-reaching fracture zones in crystalline basement consists of recording a temperature profile at the beginning of downhole measurements. Obtained after the end of drilling and coring operations, during which relatively cold fluids (in the case of Hole 504B) are being injected within such fracture zones, the temperature profile exhibits slight decreases in zones inferred to be relatively permeable.

Such a profile was recorded at the end of coring operations during Leg 140 (Dick, Erzinger, Stokking, et al., 1992). The slight changes in temperature are amplified in the temperature gradient display (Fig. 8 ), and several large peaks in thermal gradient coincide with a maximum in DLL-derived or clay-corrected porosity estimate. As the temperature data were recorded almost immediately after coring of the bottom $150 \mathrm{~m}$ (a few days), from 1850 mbsf onward then, slight oscillations in gradient profile are related to a significant transient heat anomaly, and shifting to higher values cannot be interpreted in terms of the presence of permeable zones. A few peaks in porosity are found to correspond to a small thermal anomaly (i.e., $1140 \mathrm{mbsf}$ ), whereas some estimates coincide with a gradient excursion (1225 mbsf).

The next step in the analysis consists in relating the presence of fractures, temperature anomalies, and the stress field. Borehole shape from BHTV acoustic calipers or, in some cases, FMS dual calipers as well as borehole inclination (Fig. 3), or borehole surface images (BHTV or FMS) may provide stress-related data. FMS dual-caliper data are analyzed in the following against previous porosity estimates.

\section{Borehole Elongations and Stress}

The hole size measured by the FMS shows large values in the upper part of the hole (from the casing shoe down to $1000 \mathrm{mbsf}$ ), and values generally under $12 \mathrm{in}$. below $1500 \mathrm{mbsf}$ (Fig. 3). In the deeper part of Hole 504B, a few narrow intervals near 1720 mbsf (the site of a small temperature gradient anomaly; Fig. 9) and a 70-m-long section from 1975 to $2045 \mathrm{mbsf}$ are characterized by the presence of large borehole elongations, with values of the long axis of the borehole exceeding $14 \mathrm{in}$. 

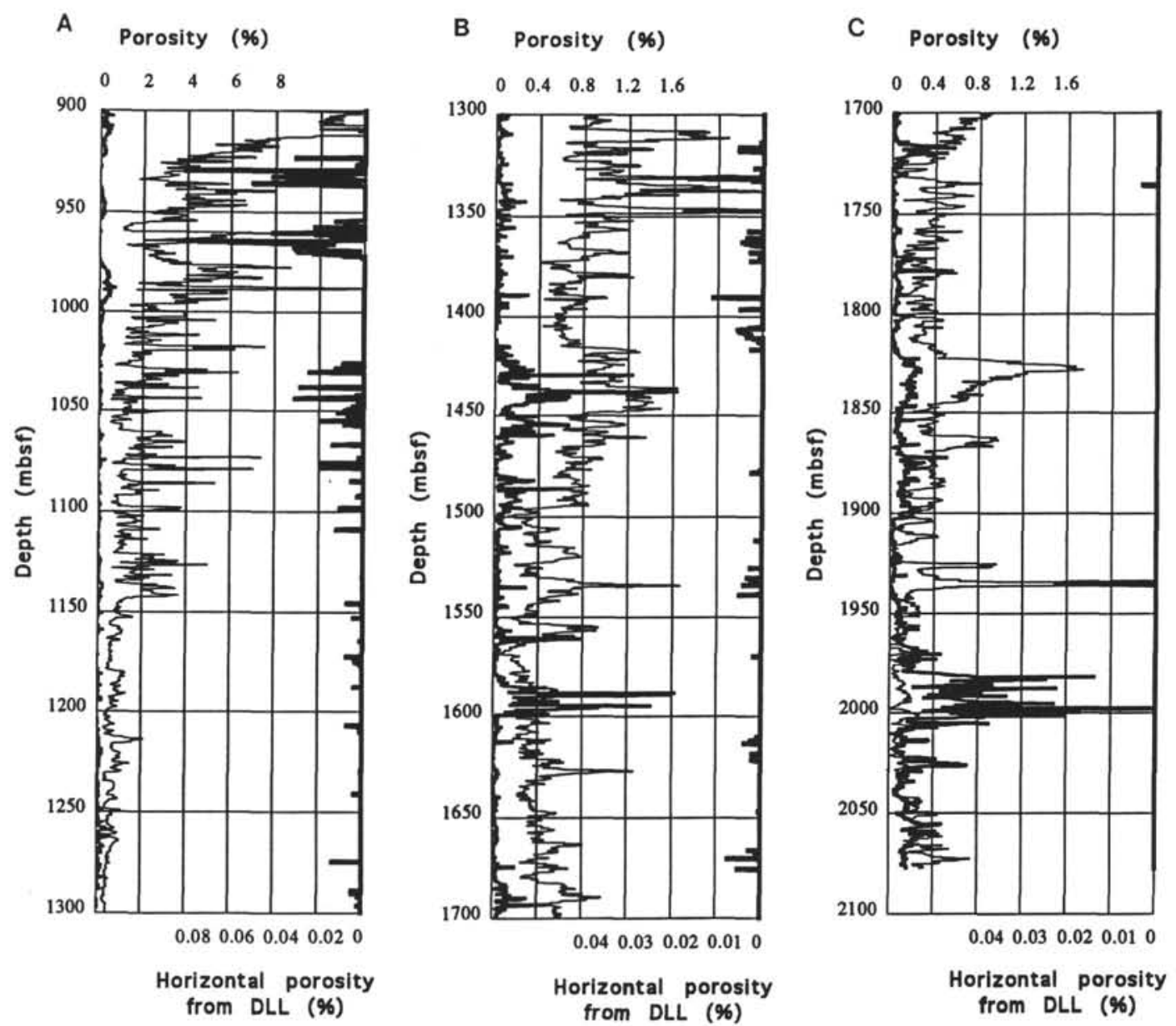

Figure 7. A. From 900 to $1300 \mathrm{mbsf}$, a DLL-derived vertical porosity (heavy line) with clay-corrected estimate (thin line) computed with a pore-volume tortuosity $\tau_{V}{ }^{2}$ of 10 presented on the left side of the diagram. DLL-derived horizontal porosity (heavy line) is presented on the right side of the diagram. B. From 1300 to $1700 \mathrm{mbsf}$, same curves with $\tau_{V}{ }^{2}=20$. C. From 1700 to $2100 \mathrm{mbsf}$, same curves with $\tau_{V}{ }^{2}=30$.

The presence of an elliptical borehole shape is traditionally interpreted in terms of breakouts (Bell and Gough, 1979), with the long axis of the borehole pointing toward minimum horizontal stress. From the analysis of BHTV data in the upper part of the hole, Morin et al. (1990) derived a main mode of ellipticity pointing $114^{\circ} \mathrm{N}$. This direction was proposed to represent the local minimum horizontal stress direction. A second, less important, but exactly orthogonal mode of enlargement was also found. It was, as mentioned earlier, attributed to thermal fracturing associate with drilling-related cooling of the hole caused by circulating seawater.

The two calipers measurements obtained with the FMS during Leg 148 generally show a similar bimodal distribution of enlargements, with similar azimuthal orientations at about $015^{\circ} \mathrm{N}$ and $110^{\circ} \mathrm{N}$ (Alt et al., 1993; Fig. 10). Down to about 1150 mbsf, what appears to be "traditional" borehole breakouts have very consistent orientations (Fig. 11). Below 1150 mbsf, a large scattering organized around the same mean value is observed down to about 1400 mbsf. Below 1400 mbsf, borehole elongation are far less frequent, and in most cases located in front of fracture zones inferred from porosity estimates. As a consequence and besides corresponding to the traditional definition of breakouts, these elongations could as well indicate the sense of shear along one of the detected plane. Slip along the surface could then be favored by coring and drilling operations, and such issues may only be resolved once borehole images are entirely analyzed. Local ruptures in front of such porous section could also be the sign of locally reduced effective stresses, thereby that of subhydrostatic pore pressure in the conduits.

For the bottom $200 \mathrm{~m}$ of the hole, borehole elongation azimuths with caliper differences larger than 1.5 in. have been plotted vs. depth with small crosses in Figure 12. Whereas the depth-azimuth plot does not define these directions extremely well, a histogram of these elongations provide much clearer descriptions with a sharp peak at $015^{\circ} \mathrm{N}$ (Fig. 12). This direction might be compared to that of single near-vertical fracture traces (with dips $>85^{\circ}$ ) mapped at the borehole surface from FMS images (Ayadi et al., this volume). About 200 of them were described over the analyzed interval and plotted vs. depth on Figure 12 (with solid circles). The two azimuthal histograms are in excellent agreement, with more scattering though in the fracture data set. Moreover, steep fractures and borehole enlargements are found to coincide at depth, in particular over a 70-m-long interval (19752045 mbsf).

This large number of near-vertical features is coherent with the observation of subvertical rupture planes in the core (Alt et al., 1993), as rupture would certainly be favored along the fracture plane mapped from FMS images. From 1975 to 2005 mbsf, the large number of subvertical planes detected from DLL data prove that ruptures meeting the borehole surface and imaged in the long axis direction of the borehole with the FMS might also extend deeper into the rock. Such a strong fracturing at depth into the rock is not present below $2005 \mathrm{mbsf}$ and might therefore be related to the cooling performed 


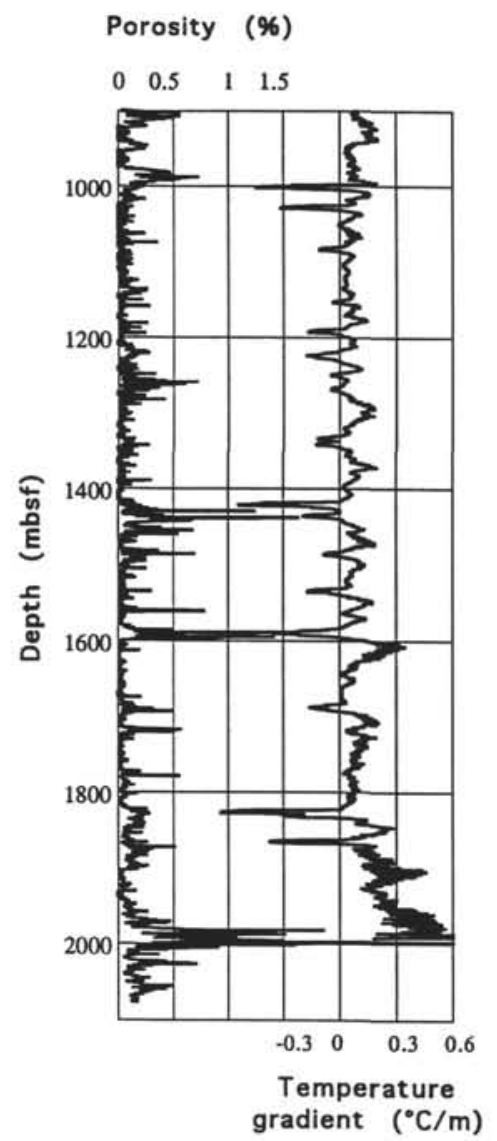

Figure 8. DLL-derived vertical fracture porosity and temperature gradient recorded at the end of coring operations during Leg 140.

before drilling at the beginning of Leg 148. A similar feature might be present at $1720 \mathrm{mbsf}$.

\section{CONCLUSION}

With the ongoing mapping of FMS images recorded during ODP Leg 148, the present approach should yield important information concerning the behavior of a fractured massif subjected to highly deviatoric stresses and, possibly, high pore pressure. The detailed analysis of downhole measurements in the sheeted dikes complex of Hole 504B and FMS images recorded at the bottom of Hole 504B yields a very precise description of the fractured dolerites. Subvertical features dominate throughout, and subhorizontal structures are nearly absent from the bottom-half of the section. A large majority of the features detected with the FMS trend, along a $015^{\circ} \mathrm{N}$ strike direction, which is that of regional $\mathrm{SH}_{\max }$ orientation. As the detection of fractures near the borehole surface with the FMS is favored for those trending in this direction, such a stress-controlled "re-opening" would certainly impact the permeability tensor of the crust, forcing fluid circulation in this $015^{\circ} \mathrm{N}$ direction.

Two zones with intense near-vertical fracturing are detailed (1920-1950 and 1975-2005 mbsf). The top one is characterized by subhorizontal structures and the site of a change in hole deviation, possibly in relation with a change in structure orientation near the present bottom of the hole. A large number of near-vertical fractures are reported from FMS images in the bottom section. These steep features coincide in azimuthal direction with that of borehole enlargements, which might arise for failures generated in tension. These borehole enlargements developing in the direction of tensile failure consequently confirm earlier determinations of $\mathrm{SH}_{\max }$ orientation. Near 1720 mbsf, similar features are also detected.

Located at the bottom of the section drilled during Leg 140, the former was cooled at the beginning of Leg 148 to protect the core bit from high temperatures. The latter corresponds to a zone where fishing operations were conducted during Leg 137. It is therefore likely that borehole enlargements and near-vertical fracturing detected in these two zones originate in fishing or specific cooling operations. Consequently, thermal stresses should whenever possible be kept to a minimum to avoid a rapid degradation of the borehole surface, with the development of numerous cracks, failure in the $\mathrm{SH}_{\max }$ direction, and the eventual clogging of the drilling assembly as encountered in many occasions near the base of Hole 504B.

\section{ACKNOWLEDGMENTS}

The authors wish to thank the detailed and constructive reviews of Chryseis Fox, Andrew Fisher, and Peter Blum. The FMS images recorded in the bottom $200 \mathrm{~m}$ of Hole 504B were analyzed with the FRACVIEW software of Schlumberger. This work was supported in 1994 by the "Marine Geosciences" ODP support program of CNRS, in France.

\section{REFERENCES}

Alt, J.C., Kinoshita, H., Stokking, L.B., et al., 1993. Proc. ODP, Init. Repts., 148: College Station, TX (Ocean Drilling Program).

Archie, G.E., 1942. The electrical resistivity log as an aid in determining some reservoir characteristics. J. Pet. Technol., 5:1-8.

Becker, K., 1985. Large-scale electrical resistivity and bulk porosity of the oceanic crust, Deep Sea Drilling Project Hole 504B, Costa Rica Rift. In Anderson, R.N., Honnorez, J., Becker, K., et al., Init. Repts. DSDP, 83: Washington (U.S. Govt. Printing Office), 419-427.

Bell, J.S., and Gough, D.I., 1979. Northeast-southwest compressive stress in Alberta: evidence from oil wells. Earth Planet. Sci. Lett., 45:475-482.

Brace, W.F., Orange, A.S., and Madden, T.R., 1965. The effect of pressure on the electrical resistivity of water-saturated crystalline rocks. J. Geophys. Res., 70:5669-5678.

Carman, P.C., 1956. Flow of Gases Through Porous Media: San Diego (Academic).

Clavier, C., Coates, G., and Dumanoir, J., 1986. The theoretical and experimental basis for the "dual-water" model for the interpretation of shaly sands. In Schmidt, A. (Ed.), Openhole Well Logging. Soc. Pet. Eng., SPE Repr. Ser., 21:357-372.

Dick, H.J.B., Erzinger, J., Stokking, L.B., et al., 1992. Proc. ODP, Init. Repts., 140: College Station, TX (Ocean Drilling Program).

Ellis, D.V., 1987. Well Logging for Earth Scientists: New York (Elsevier).

Gueguen, Y., and Dienes, J., 1989. Transport properties of rocks from statistics and percolation. Math. Geol., 21:1-13.

Hey, R., Johnson, G.L., and Lowrie, A., 1977. Recent plate motions in the Galapagos area. Geol. Soc. Am. Bull., 88:1385-1403.

Johnson, D.L., and Schwartz, L.M., 1989. Unified theory of geometrical effects in transport properties of porous media. Log Analyst, 30:98. (Abstract)

Johnson, D.L., and Sen, P.N., 1988. Dependence of the conductivity of a porous medium on electrolyte conductivity. Phys. Rev. B, 37:3502-3510.

Langseth, M.G., Mottl, M.J., Hobart, M.A., and Fisher, A., 1988. The distribution of geothermal and geochemical gradients near Site 501/504: implications for hydrothermal circulation in the oceanic crust. In Becker, K., Sakai, H., et al., Proc. ODP, Init. Repts., 111: College Station, TX (Ocean Drilling Program), 23-32.

Lüthi, S.M., and Banavar, J.R., 1988. Application of borehole images to three-dimensional geometric modeling of eolian sandstone reservoirs, Permian Rotliegende, North Sea. AAPG Bull., 72:1074-1089.

Lüthi, S.M., and Souhaité, P., 1990. A method for fracture extraction and width determination from electrical borehole scans. Geophysics, 55:821833.

Moos, D., and Zoback, M.D., 1990. Utilization of observations of well bore failure to constrain the orientation and magnitude of crustal stresses: application to continental, Deep Sea Drilling Project, and Ocean Drilling Program boreholes. J. Geophys. Res., 95:9305-9325. 
Morin, R.H., Newmark, R.L., Barton, C.A., and Anderson, R.N., 1990. State of lithospheric stress and borehole stability at Deep Sea Drilling Project Site 504B, eastern Equatorial Pacific. J. Geophys. Res., 95:9293-9303.

Newmark, R.L.. Anderson, R.N., Moos, D., and Zoback, M.D., 1985. Sonic and ultrasonic logging of Hole 504B and its implications for the structure, porosity, and stress regime of the upper $1 \mathrm{~km}$ of the oceanic crust. In Anderson, R.N., Honnorez, J., Becker, K., et al., Init. Repts. DSDP, 83: Washington (U.S. Govt. Printing Office), 479-510.

Pape, H., Riepe, L., and Schopper, J.R., 1985. Petrophysical detection of microfissures in granites. Trans. SPWLA 26th Annu, Logging Symp., P1P17.

Pape, H., and Worthington, P.F., 1983. Electrical conductivities in reservoir rocks explained by a model of structure and surface area. Trans. $8 \mathrm{th}$ Eur. Form. Eval. Symp.

Pezard, P.A., 1990. Electrical properties of mid-ocean ridge basalt and implications for the structure of the upper oceanic crust in Hole 504B. J. Geophys. Res., 95:9237-9264.

Pezard, P.A., and Anderson, R.N., 1990. Electrical resistivity, anisotropy, and tectonic context. Trans. SPWLA 3/st Annu. Logging Symp., paper M.

Pezard P.A., Lovell, M.A., and ODP Leg 126 Shipboard Scientific Party, 1990. Downhole images: electrical scanning reveals the nature of subsurface oceanic crust. Eos, 71:709.
Ucok, H., 1980. Temperature dependence of the electrical resistivity of aqueous salt solutions and solution-saturated porous rocks [Ph.D. thesis]. Univ. California, Los Alamos, NM.

Von Herzen, R.P., Francis, T.J.G., and Becker, K., 1983. In situ large-scale resistivity of ocean crust, Hole 504B. In Cann, J.R., Langseth, M.G.. Honnorez, J., Von Herzen, R.P., White, S.M., et al., Init. Repts. DSDP, 69: Washington (U.S. Govt. Printing Office), 237-244.

Waxman, M.H., and Smits, L.J.M., 1968. Electrical conductivities in oilbearing shaly sands. SPEJ, Soc. Pet. Eng. J., 8:107-122.

Wilkens, R., Schultz, D., and Carlson, R., 1988. Relationship of resistivity, velocity, and porosity for basalts from downhole well-logging measurements in Hole 418A. In Salisbury, M.H., Scott, J.H., et al., Proc. ODP, Sci. Results, 102: College Station, TX (Ocean Drilling Program), 69-75.

Winsauer, W.O., and McCardell, W.M., 1953. Ionic double-layer conductivity in reservoir rocks. Trans. AIME, 198:129-134.

Date of initial receipt: 23 August 1994

Date of acceptance: 28 May 1995

Ms 148SR-137
A

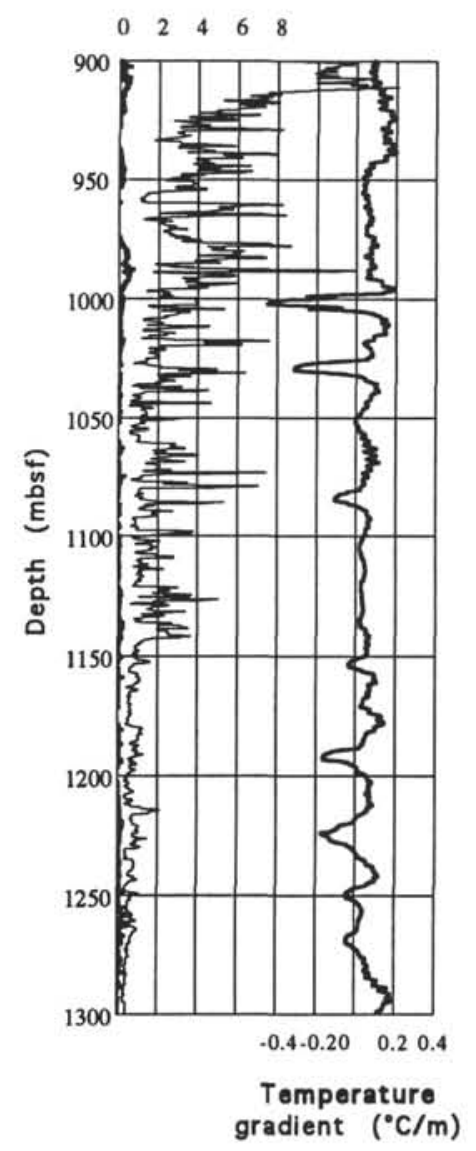

B Porosity (\%)

$\begin{array}{llll}0 & 0.5 & 1 & 1.5 \quad 2\end{array}$

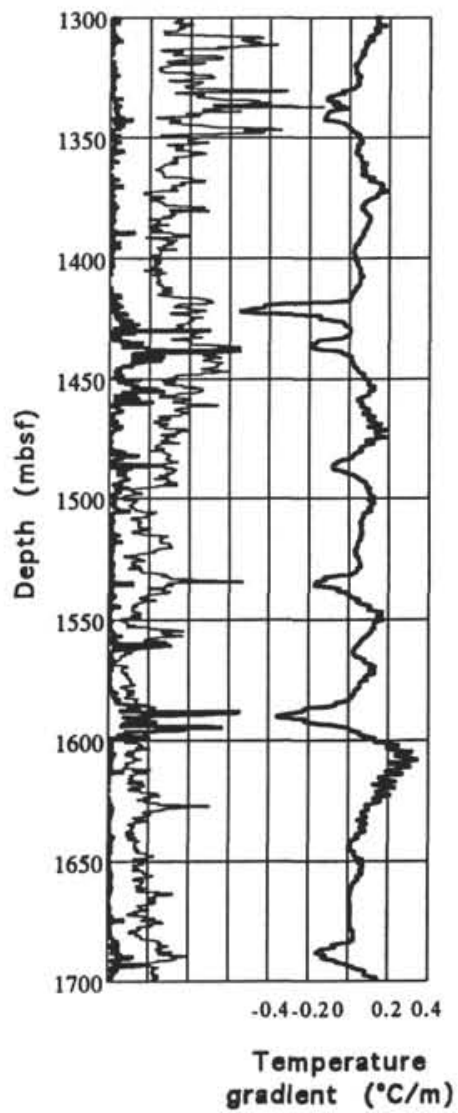

C Porosity (\%)

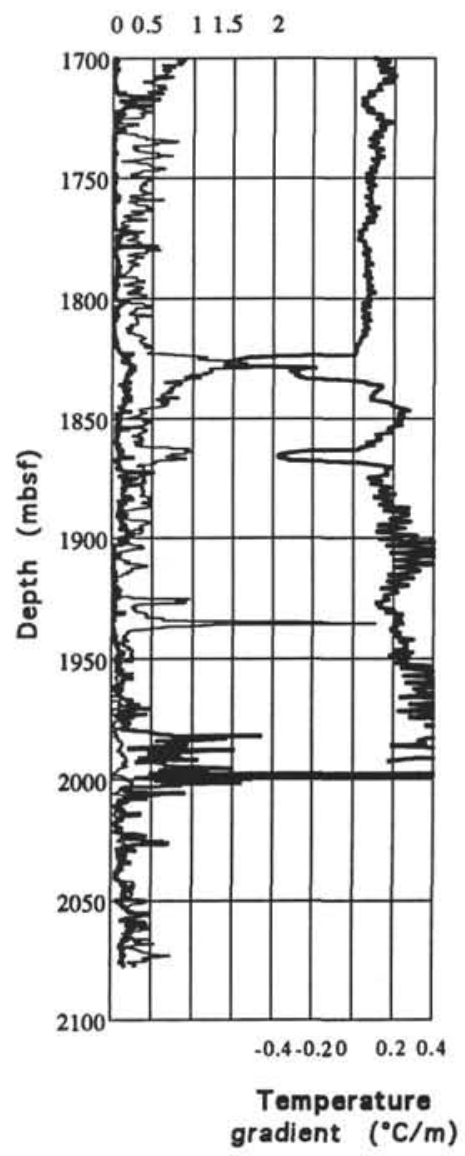

Figure 9. A. From 900 to 1300 mbsf, DLL-derived vertical porosity (heavy line) with clay-corrected estimate (thin line) computed with a pore-volume tortuosity $\tau_{V}{ }^{2}$ of 10 presented on the left side of the diagram. Temperature gradient recorded at the end of coring operations during Leg 140 (heavy line) presented on the right side of the diagram. B. From 1300 to $1700 \mathrm{mbsf}$, same curves with $\tau_{v}^{2}=20$. C. From 1700 to $2100 \mathrm{mbsf}$, same curves with $\tau_{v}{ }^{2}=30$. 

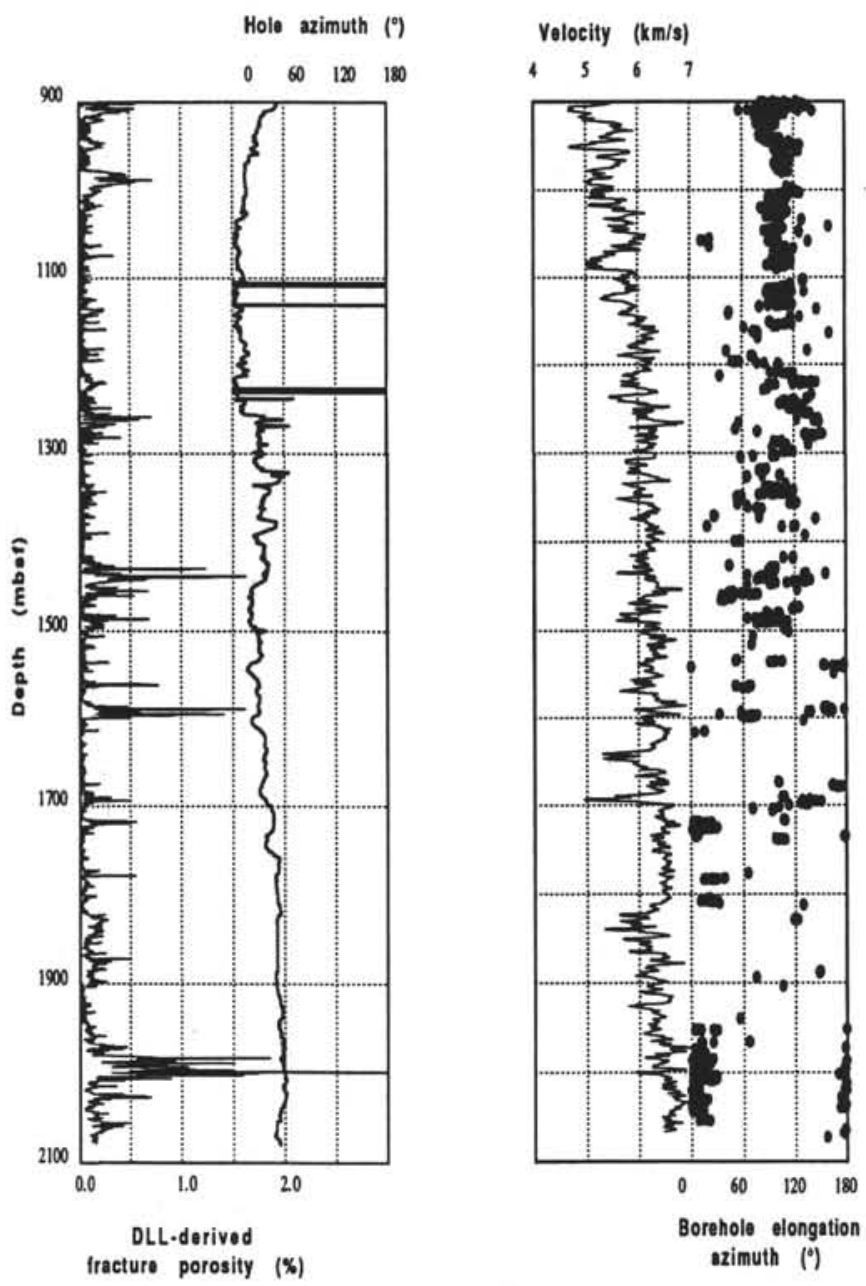

Figure 10. On the left, DLL-derived vertical fracture porosity and hole azimuth from FMS inclinometry showing changes in hole azimuth. On the right, compressional velocity with location of borehole enlargements plotted vs. strike when $[\mathrm{C} 1-\mathrm{C} 2]$ is greater than $1.5 \mathrm{in}$. 
A

Porosity (\%)

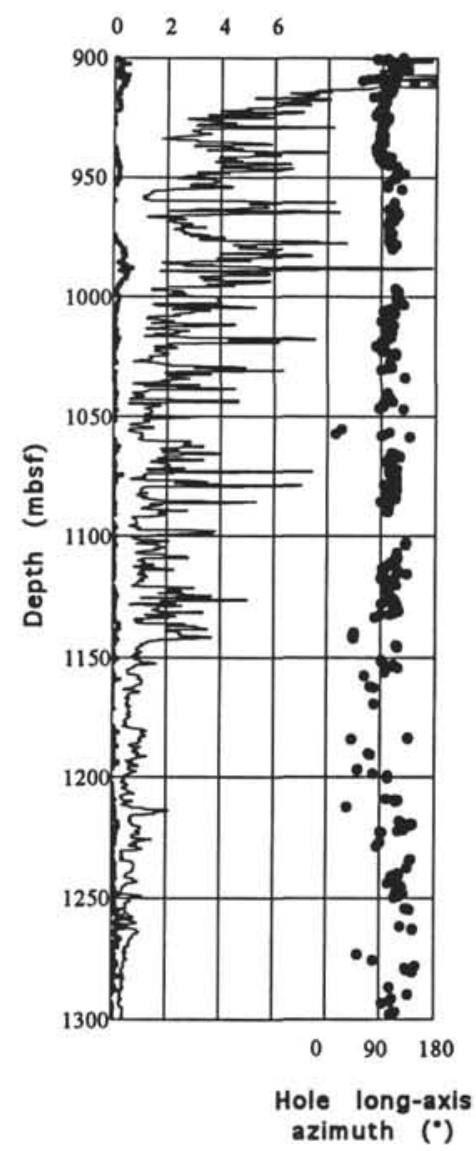

B

Porosity (\%)

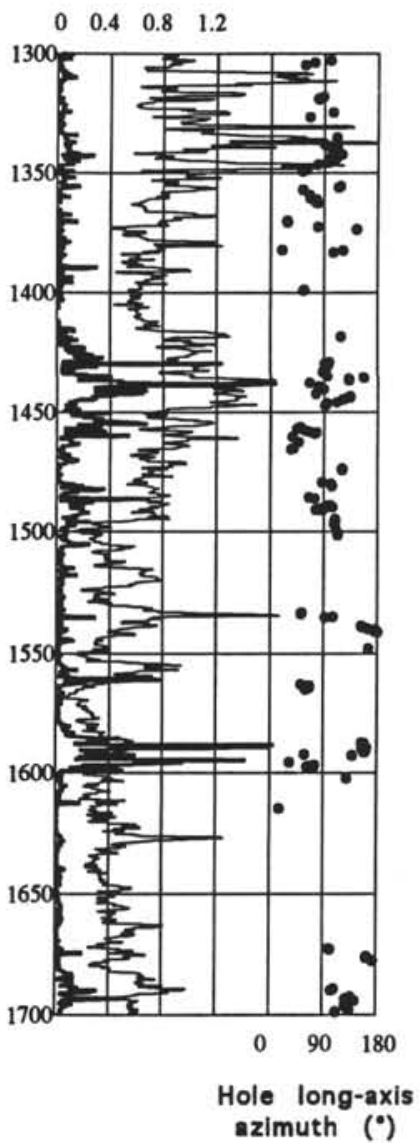

C Porosity (\%)

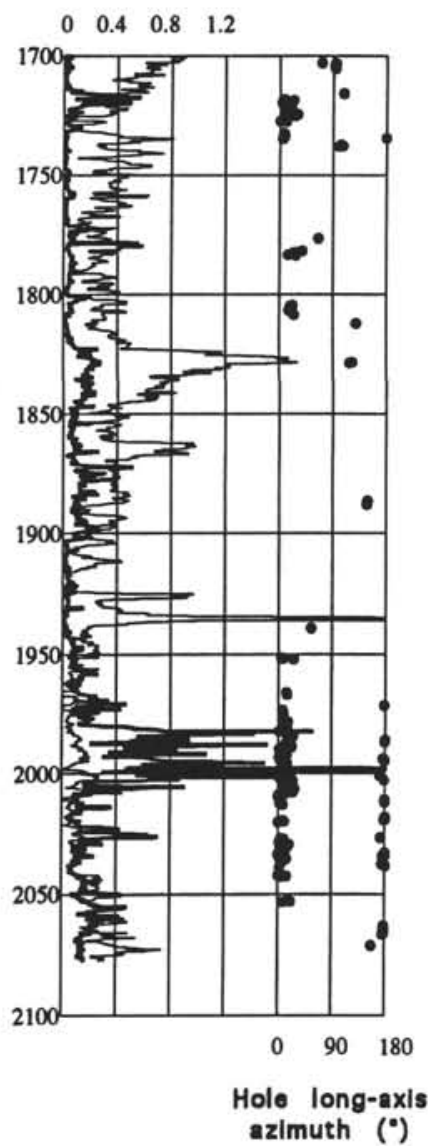

Figure 11. A. From 900 to 1300 mbsf, DLL-derived vertical porosity (heavy line) with clay-corrected estimate (thin line) computed with a pore-volume tortuosity $\tau_{V}{ }^{2}$ of 10 presented on the left side of the diagram. Location of borehole enlargements plotted vs. strike when [C1-C2] is greater than 1.5 in. presented on the right side of the diagram. B. From 1300 to 1700 mbsf, same curves with $\tau_{V}{ }^{2}=20$. C. From 1700 to 2100 mbsf, same curves with $\tau_{V}{ }^{2}=30$. 
A DLL-derived
porosity (\%)
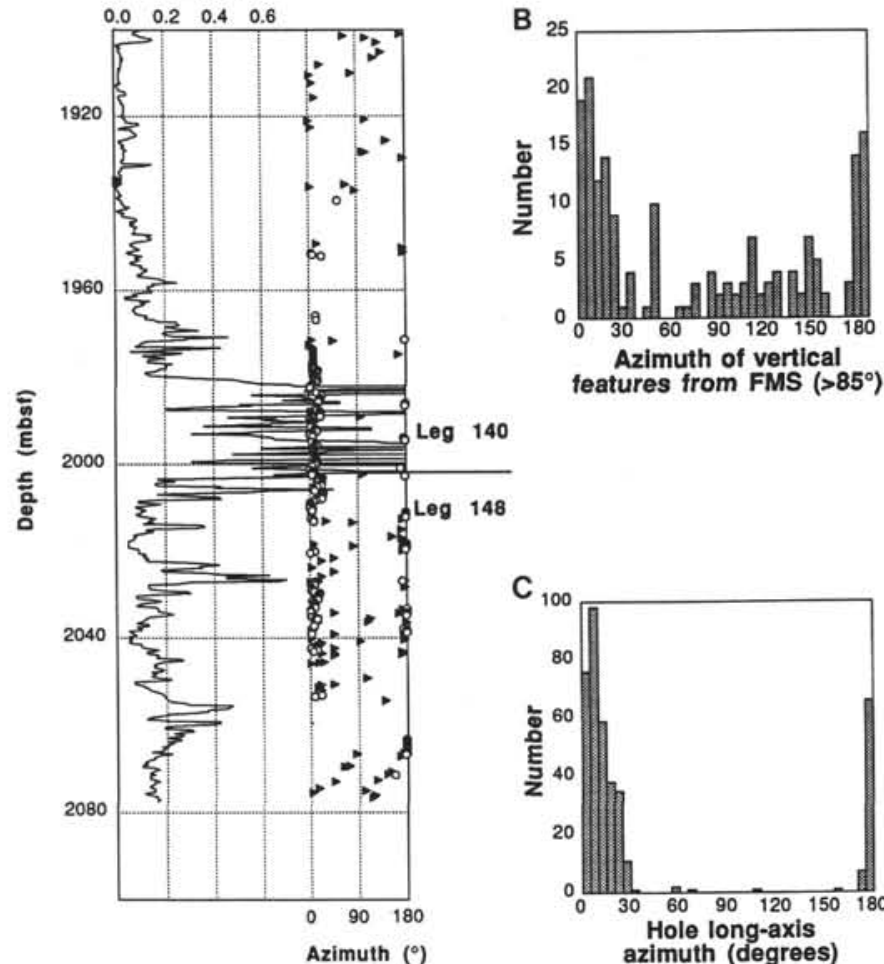

Figure 12. A. Diagram representing filtered azimuth of near-vertical features (with dips $\geq 85^{\circ}$ ) from FMS image analyses (triangles), and azimuth of borehole elongations in the bottom $200 \mathrm{~m}$ of Hole 504B from FMS calipers (circles). Histograms representing azimuth of vertically induced features from (B) FMS images, and (C) borehole long-axis from FMS calipers. 